\title{
$\mathcal{L}_{\text {nvestigación IMA }}^{\text {REVISA }}$
}

\section{LA INVESTIGACIÓN: UNA ACTIVIDAD DE RUTINA}

\author{
CT MARCOS MANUEL GUZMÁN \\ Jefe Sección Investigación IMA
}

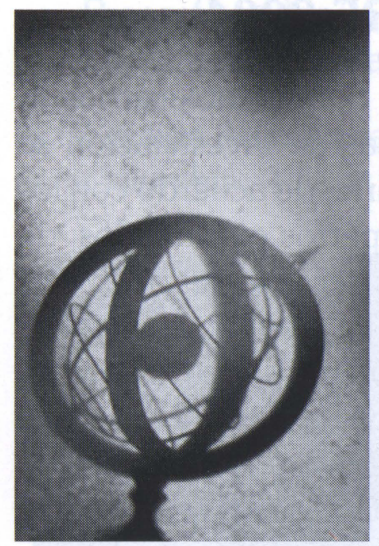

La investigación en general es un término que muy seguramente a la gran mayoría de las personas les llega a causar confusión o hasta rechazo, más cuando se trata de la investigación científica, la cual se tiene como en un pedestal imaginando que es algo diáfano y hasta sublime pero percibiendo a quienes logran hacer investigación como personas muy experimentadas, con unas características muy especiales, quienes se concentran todo el tiempo detrás de un gigantesco escritorio y se encierran en unos centros muy especializados de la ciencia y del saber con unos letreros muy modestos como "prohibido interrumpir... genios pensando".

Sin embargo, en el transcurrir de la historia nos damos cuenta que la investigación científica no es nada de ésto, sino que por el contrario tiene que ver con personas de la vida normal, comunes y corrientes, que surgen con la realidad misma, con las actividades de cada día relacionadas con la rutina diaria de trabajo, de escuela, de conflictos, de aspectos económicos, políticos, sociales, familiares, laborales y demás asuntos de la vida misma.

Este supuesto lo podemos confrontar con la vida de los distintos investigadores que han surgido en el transcurrir del tiempo, como es el caso de ISAAC NEWTON, quien durante un descanso en el campo de repente lo sorprendió la caída de una manzana en su cabeza lo cual despertó una gran curiosidad y después de pensar durante algún tiempo indagó tal acontecimiento mediante un proceso investigativo hasta formular la ley de la gravedad, vigente actualmente en el planeta. Del mismo modo le sucedió al señor ARQUÍMIDES, quien en una de sus actividades de rutina como la de bañarse, descubrió que en el proceso de sumergirse en la tina había un desplazamiento de agua igual a la masa de su cuerpo, descubriendo así una forma de medir la masa de los objetos y estableciendo lo que actualmente se conoce como la ley de los cuerpos.

La investigación científica es como cualquier otra actividad, solo que es más rigurosa y cuidadosamente realizada. Según KERLINGER, citado por HERNÁNDEZ (1975) se podría definir como "sistemática, controlada, empírica y critica, de proposiciones hipotéticas sobre las presumidas relaciones entre fenómenos naturales". Al hablar de "sistemática y controlada" implica una disciplina constante para realizarla, sin dejar los hechos a la casualidad. "Empírica" significa que se basa en fenómenos observables de la realidad y "crítica”, es decir que elimina las preferencias de tipo personal y los juicios de valor. Partiendo de esta descripción, la investigación puede cumplir dos propósitos fundamentales: 
La producción de conocimiento y de teorías (investigación básica)

La resolución de problemas prácticos (investigación aplicada).

Con la aplicación del proceso de investigación científica se generan nuevos conocimientos, los cuales a su vez producen nuevas ideas $e$ interrogantes y es de esta manera que avanza la ciencia y la tecnología.

Para adelantar el proceso investigativo es necesario tener en cuenta unos parámetros pedagógicos, los cuales van de acuerdo al tipo de escuela o centro de investigación, entre los cuales mencionaremos el planteamiento del problema, que no es otra cosa que afirmar y estructurar más formalmente la idea de investigación, desarrollando tres elementos: objetivos, preguntas de investigación y la justificación. Estos tres elementos deben guiar el proceso de indagación. Los objetivos y preguntas de investigación deben ser congruentes entre si e ir en la misma dirección; los objetivos establecen qué se pretende con dicha investigación, las preguntas indican que respuestas deben encontrarse y la justificación por qué debe hacerse tal investigación. Los criterios principales para evaluar el valor potencial de una investigación son entre otros convivencia, relevancia social, implicaciones prácticas, valor teórico, viabilidad y utilidad metodológica.

Otro de los pasos es el marco teórico, para lo cual se hace necesario consultar las fuentes de tipo teórico relacionado con el problema de investigación y extraer la información de mayor interés relacionada con el tema a investigar.

Con esta corta descripción y algunos aspectos de investigación pretendo que nos integremos como comunidad aérea y empecemos a desarrollar iniciativas del proceso investigativo desde los diferentes lugares de nuestra geografía nacional como un punto de partida para el desarrollo de la ciencia y la tecnología, con visión de lo que será nuestra Fuerza Aérea en un horizonte cercano, teniendo en cuenta que la "investigación es el camino al mejoramiento continuo de la aviación militar"

\section{LINEAS DE INVESTIGACION PARA EL CORTO PLAZO (SEGUNDO SEMESTRE 2002 PRIMER SEMESTRE 2004)}

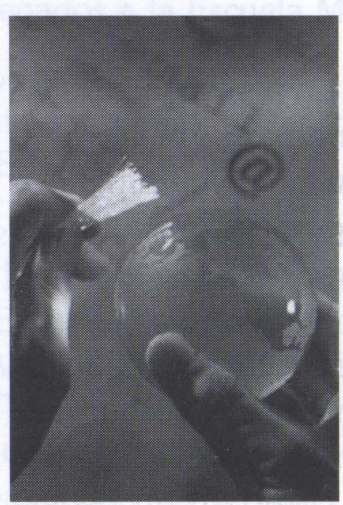

Para establecer las líneas de investigación se parte, de acuerdo con los expertos consultados, de las necesidades puntuales en el área de administración y logística, cuyo sustento se halla en los problemas encontrados por la Contraloría General de la República en los siguientes temas:

- Estados Contables: Repetitivas y recurrentes inconsistencias con los principios de contabilidad generalmente aceptados en Colombia.

- Gestión: La gestión contractual no se ajusta a la ley ni a las normas de austeridad.

El sistema de Control Interno no garantiza eficiente y efectivo cumplimiento de los objetivos y misión institucional.

- La gestión administrativa es deficiente frente a las normas presupuestales, contables y contractuales por no aplicar a cabalidad los principios de eficiencia, eficacia y economía.

- Bajo nivel de aplicabilidad y rotación de los inventarios de repuestos y herramientas para las acciones.

- Debilidades o ausencia de mecanismos de control y coordinación tanto internas como externas.

- Incumplimiento a lo previsto en el Estatuto Orgánico de Presupuesto y demás normas presupuestales, incurriendo en errores y omisiones en la rendición de cuentas e informes.

Estos problemas pueden ser explorados a través de una gran línea de investigación denomi- 
nada "SIMULACIÓN DE PROCESOS" con proyectos como:

- Integración de Procesos Logísticos - Contables - Contractuales y Presupuestales.

- Procesos pedagógicos y metodológicos en las Escuelas de Formación.

- Gestión Administrativa en la Fuerza Aérea de Colombia.

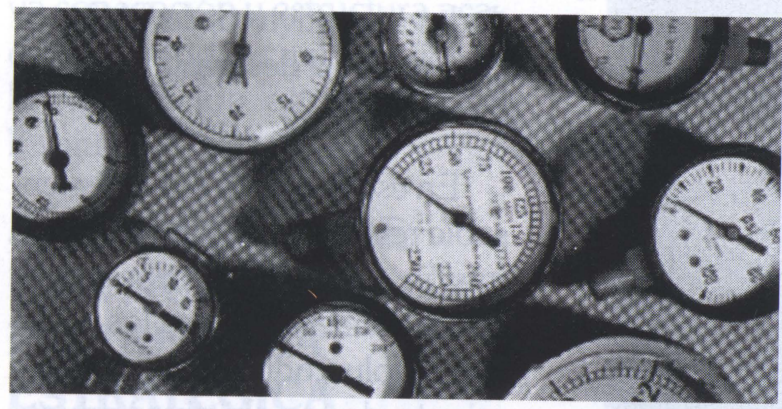

\section{LINEA DE}

\section{INVESTIGACIÓN A}

MEDIANO PLAZO

\section{(SEGUNDO SEMESTRE 2004 SEGUNDO SEMESTRE 2005)}

Para determinar las líneas de investigación en el área de ingeniería se parte del planteamiento que sobre el particular ha elaborado la Dirección del Programa de Ingeniería Mecánica de EMAVI como respuesta a lo dispuesto en el Decreto 792 del 8 de Mayo de 2001. "Por el cual se establecen estándares de calidad en programas académicos de pregrado de Ingeniería". Para tal efecto y con la colaboración de otros expertos se proponen las siguientes líneas de investigación:

METEOROLOGIA Y FACTORES AMBIENTALES

\section{FISIOLOGÍA Y SEGURIDAD DE VUELO}

AERODINÁMICA, PROPULSIÓN, COMBUSTIÓN (EMAVI E IMA/ESUFA).

DOCUMENTACION Y HOMOLOGACIÓN DE INNOVACIONES TECNOLÓGICAS LOGRADAS POR EL PERSONAL FAC (IMA) ESUFA)
LINEAS DE

INVESTIGACIÓN A

LARGO PLAZO

(A PARTIR PRIMER SEMESTRE 2006)

PRODUCCION DE ENERGÍA ALTERNATIVA

DISEÑO, CONTRUCCIONE INTEGRACION DE PARTES O COMPONENTES AERONAVES Y PLATAFORMAS AÉREAS TIPO AUV.

SENSORES Y MANEJO DE SEÑALES E IMÁGENES.

\section{Jefatura de Educación Aeronáutica}

FAC

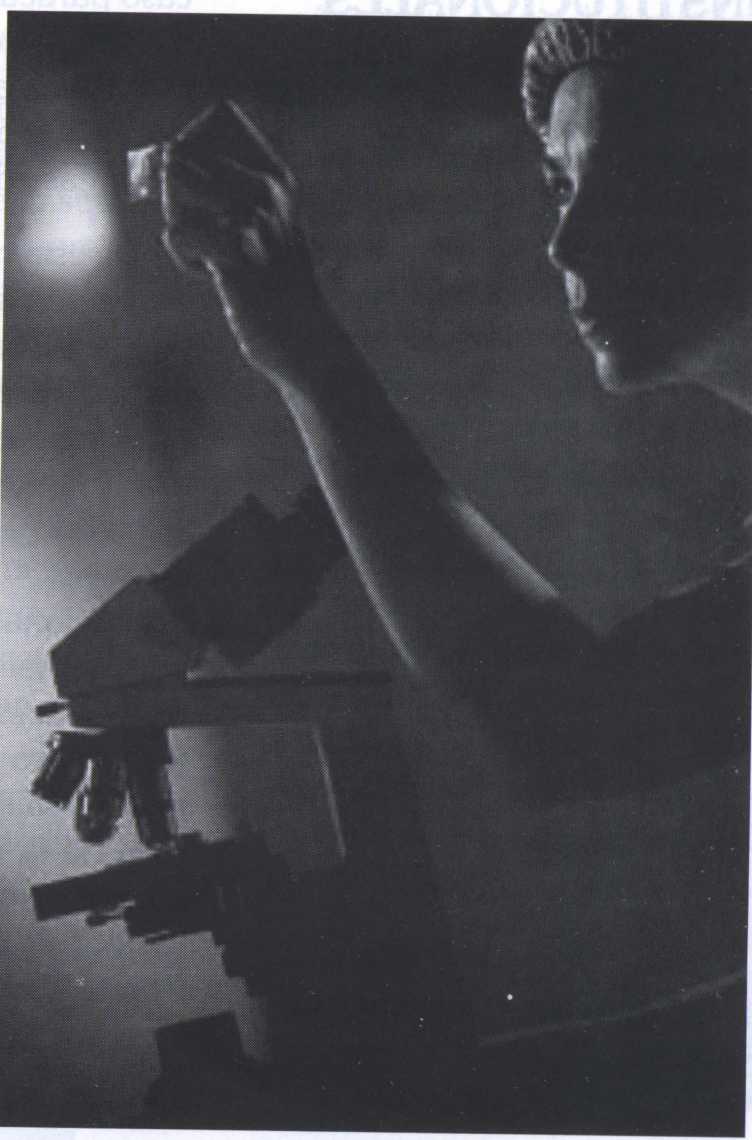

